[white paper]

Diamond Open Access

\title{
$n$ e 2 elevado a $n$ menos 1 não primos
}

\author{
Colaboração Matemática Aberta ${ }^{1}$ \\ 23 de Janeiro de 2021
}

\begin{abstract}
Resumo
Apresentamos uma demonstração didática do teorema que diz:

Se $n$ é um inteiro maior que 1 e $n$ não é primo, então $2^{n}-1$ não é primo.
\end{abstract}

palavras-chave: teoria de números, teorema, números não primos

A versão mais atualizada deste artigo está disponivel em https://osf.io/k67em/download

\section{Introdução}

1. Esses livros são excelentes referências para iniciar os estudos neste maravilhoso universo das demonstrações matemáticas [1-3].

\section{Teorema}

2. Se $n$ é um inteiro maior que 1 e $n$ não é primo, então $2^{n}-1$ não é primo [1].

${ }^{1}$ Todos os autores com suas afiliações aparecem no final deste artigo. 


\section{Demonstração de (2)}

3. Como $n$ não é primo, ele é um número composto, então existem inteiros positivos $a$ e $b$ tais que $a<n, b<n$ e $n=a b$.

4. Note que (3) é a definição de números compostos.

5. Precisamos definir dois números $x$ e $y$ para provarmos o seguinte:
(a) $x y=2^{n}-1$,
(b) $x<2^{n}-1$,
(c) $y<2^{n}-1$.

6. Note que (5.a) garante que o termo que queremos provar pode ser escrito como o produto de dois números e $(5 . b, c)$ garantem que nem $x$, nem $y$ sejam iguais a 1 .

7. Se $x$ ou $y$ fosse igual a 1 , o número $2^{n}-1$ poderia não ser composto, mas sim primo.

8. Portanto, provar (5) significa provar (1).

9. A proposição (10) a seguir é o insight criativo, o principal responsável pelo sucesso desta demonstração.

10. Sejam

$$
\begin{gathered}
x=2^{b}-1, \\
y=1+2^{b}+2^{2 b}+\ldots+2^{(a-2) b}+2^{(a-1) b} .
\end{gathered}
$$

11. Em (10), $x$ e $y$ foram definidos dessa forma para que possamos ter $x y=2^{n}-1$.

12. Vamos mostrar (11).

13. De (10),

$$
x y=\left(2^{b}-1\right) \cdot\left(1+2^{b}+2^{2 b}+2^{3 b}+\ldots+2^{(a-2) b}+2^{(a-1) b}\right) .
$$


14. Fazendo a distributiva de $2^{b}$ e em seguida de -1 com o parêntesis da direita de (13), $x y=2^{b} \cdot\left(1+2^{b}+2^{2 b}+\ldots+2^{(a-2) b}+2^{(a-1) b}\right)-\left(1+2^{b}+2^{2 b}+\ldots+2^{(a-2) b}+2^{(a-1) b}\right)$.

15. Fazendo a distributiva de $2^{b}$,

$$
x y=\left(2^{b}+2^{2 b}+2^{3 b}+\ldots+2^{(a-1) b}+2^{a b}\right)-\left(1+2^{b}+2^{2 b}+2^{3 b}+\ldots+2^{(a-1) b}\right) .
$$

16. Após a igualdade de (15), o último termo do primeiro parêntesis vem deste cálculo, $2^{b} \cdot 2^{(a-1) b}=2^{b} \cdot 2^{a b-b}=2^{b+a b-b}=2^{a b}$.

17. Note que, em (15), $2^{b}$ da esquerda cancela com $-2^{b}$ da direita, $2^{2 b}$ da esquerda cancela com $-2^{2 b}$ da direita, $2^{3 b}$ cancela com $-2^{3 b}$, e assim sucessivamente.

18. Assim,

$$
x y=2^{a b}-1 .
$$

19. De (3), $n=a b$, então

$$
x y=2^{n}-1 .
$$

20. De (3), $b<n$.

21. De (10), $x=2^{b}-1$.

22. De (20) e (21),

$$
x=2^{b}-1<2^{n}-1 .
$$

23.

$$
x<2^{n}-1
$$

24. De (3), temos que

$$
a b=n>a .
$$

25.

$$
a b>a
$$


26. De (3), como a é um inteiro positivo, dividindo (25) por $a$, temos

$$
b>1 .
$$

27. Como $b>1$, da definição de $x$ em (10),

$$
x=2^{b}-1>2^{1}-1=1 .
$$

28.

$$
x>1
$$

29. Multiplicando os dois lados da desigualdade $x>1$ por $y$, que é maior do que zero, temos

$$
x y>y .
$$

30. De (19), substituindo $x y=2^{n}-1$ em (29), então

$$
y<2^{n}-1 .
$$

31. De (19), (23) e (30), concluímos que $2^{n}-1$ pode ser escrito como o produto de dois inteiros positivos $x$ e $y$, ambos menores do que $2^{n}-1$.

32. Portanto, $2^{n}-1$ NÃO é primo.

\section{Considerações Finais}

33. Provamos o teorema (2) apresentando o maior número de passos que pudemos visualizar.

\section{Ciência Aberta}

O arquivo latex para este artigo, juntamente com outros arquivos suplementares, estão disponíveis em [4]. Seja coautor(a) deste artigo, envie sua contribuição para mplobo@uft.edu.br. 


\section{Referências}

[1] Velleman, Daniel J. How to prove it: A structured approach. Cambridge University Press, 2019.

[2] Warner, Steve. Pure Mathematics for Beginners. GET 800, 2018.

[3] Warner, Steve. Abstract Algebra for Beginners. GET 800, 2018.

[4] Lobo, Matheus P. "Open Journal of Mathematics and Physics (OJMP)." OSF, 21 Apr. 2020.

https://doi.org/10.17605/osf .io/6hzyp

\section{Colaboração Matemática Aberta}

Matheus Pereira Lobo (autor principal, mplobo@uft.edu.br) $)^{1,2}$ https://orcid.org/0000-0003-4554-1372

${ }^{1}$ Universidade Federal do Tocantins (Brasil)

${ }^{2}$ Universidade Aberta (UAb, Portugal) 